\title{
Tools for analysis of business processes - a comparative analysis
}

\section{Narzędzia do analizy procesów biznesowych - analiza porównawcza}

\author{
Jakub Janicki*, Ernest Wójcik \\ Department of Computer Science, Lublin University of Technology, Nadbystrzycka 36B, 20-618 Lublin, Poland
}

\begin{abstract}
This article discusses topics in the field of business analysis, which is the basic element of the operation of modern organizations. The aim of this publication is to present and evaluate four selected tools for modeling business diagrams in BPMN notation. As part of the introduction to the topic, business processes were characterized, their analysis was defined, and the reader was introduced to the BPMN notation and the tested tools. The research methodology and its course were also defined. Then, the research was carried out in accordance with the adopted methodology. The conclusion of this work was the result of the research together with the analysis. Finally, the conducted experiments were summarized together with conclusions.
\end{abstract}

Keywords: Business processes; BPMN; business diagrams

\section{Streszczenie}

Niniejszy artykuł porusza tematy z zakresu analizy biznesowej, będącej podstawowym elementem funkcjonowania współczesnych organizacji. Celem tej publikacji jest przedstawienie i ocena czterech wybranych narzędzi do modelowania diagramów biznesowych w notacji BPMN. W ramach wprowadzenia do tematu scharakteryzowano procesy biznesowe, zdefiniowano ich analizę, a także przybliżono czytelnikowi notację BPMN i badane narzędzia. Zdefiniowano też metodykę badań i ich przebieg. Następnie przeprowadzone zostały badania zgodnie z przyjętą metodyką. Rezultatem tych prac były wyniki badań razem z analizą. Na koniec podsumowano przeprowadzone pomiary łącznie $\mathrm{z}$ wnioskami.

Stowa kluczowe: Procesy biznesowe; BPMN; diagramy biznesowe

*Corresponding author:

Email address: jakub.janicki@pollub.edu.pl (J. Janicki)

CPublished under Creative Common License (CC BY-SA v4.0)

\section{Wstęp}

Procesy biznesowe są nieodłącznym elementem każdej większej firmy. Do ich analizy stosowane są programy, które pozwalają w mniej lub bardziej efektywny sposób z nimi pracować. Liczba narzędzi służących do analizy procesów biznesowych wciąż się powiększa, w związku z czym nie jest łatwo znaleźć optymalną aplikację realizującą wszystkie potrzeby użytkowników.

W celu rzetelnego i skutecznego przeprowadzania badań, zaznajomiono się $\mathrm{z}$ wieloma materiałami naukowymi. Istotną pozycją na liście literatury jest książka o tytule "Fundamentals of Business Process Management" [1], wprowadzajaca czytelnika w temat cyklu życia procesów biznesowych. Niezwykle ważne było też zaznajomienie się $\mathrm{z}$ dokumentacją ocenianych narzędzi. Umożliwiło to poznanie pełnych funkcji programów i naukę korzystania z nich.

\section{Cel i zakres pracy}

Celem badań, będących tematem tego artykułu, jest porównanie jakości konkretnych narzędzi służących do analizy procesów biznesowych. Analiza będzie wykonana $\mathrm{z}$ wykorzystaniem następującej metodyki: zdefiniowanie sytuacji stosowania narzędzi, opracowanie kryteriów porównawczych i ich parametrów (zmiennych niezależnych), wybór metody porównania $\mathrm{z}$ wykorzystaniem zdefiniowanych kryteriów, określenie (doświadczalne) wartości zmiennych niezależnych i przeprowadzenie finalnych obliczeń. Porównanie będzie poprzedzone przeglądem narzędzi $\mathrm{i}$ wyborem czterech $\mathrm{z}$ nich do analizy porównawczej.

Zakres pracy obejmuje przegląd istniejących narzędzi do analizy procesów biznesowych, przegląd metod porównywania $\mathrm{z}$ uwzględnieniem wielu kryteriów i dobór jednej $\mathrm{z}$ nich, przeprowadzenie eksperymentu w celu określenia parametrów każdego z wybranych narzędzi, przeprowadzenie obliczeń oraz przedstawienie wniosków.

\section{Procesy biznesowe $\mathrm{i}$ ich analiza}

\subsection{Procesy biznesowe}

Procesy biznesowe, zwane również metodami biznesowymi, stanowią powiązane ze sobą zadania zmierzające $\mathrm{ku}$ osiągnięciu zamierzonego efektu. Niezależnie od nazwy funkcjonują w każdej firmie, a najistotniejszym celem każdego $\mathrm{z}$ nich jest zrozumienie potrzeb klienta, możliwości zespołu dostawcy oraz słabych i mocnych stron procesu [2]. 


\subsection{Analiza procesów}

Metodą, która pozwala przeanalizować, czy istniejące procesy spełniają założone im cele nazywa się analizą procesów. Dzięki tej metodzie zespół jest w stanie zlokalizować niekorzystne fragmenty procesu, znaleźć ich przyczynę, a także określić w jaki sposób rozwiązać problem [3].

Przy użyciu narzędzi, a także metodologii, możliwe jest spojrzenie na procesy $\mathrm{w}$ różny sposób oraz śledzenie produktywności i wydajności. Jest to istotne podczas analizy procesów, ze względu na ich złożoność z zadań, które charakteryzuje określony cel końcowy. Przy analizie koncentracja skierowana jest na obserwację sposobów zachodzących w cyklu życia, od początku do końca procesu [4].

Dzięki szerokiemu zakresowi, analiza procesów wykorzystywana jest w szerszym gronie organizacji oraz przedsiębiorstwach o coraz szerszej specjalizacji. Stosowana jest przede wszystkim do organizacji pracy, wprowadzania nowych pracowników, planowania obciążenia stanowiska oraz ustalania poziomu osiągnięć w organizacji [5].

\subsection{Business Process Model and Notation}

W skrócie BPMN, czyli "Notacja i Model Procesu Biznesowego". Jak sama nazwa wskazuje, to notacja graficzna przedstawiająca proces biznesowy. Notacja BPMN utrzymywana jest obecnie przez OMG (Object Management Group), konsorcjum, w którego skład wchodziły firmy takie jak Apple czy IBM. Stworzona została natomiast dzięki Business Process Management Initiative (BPMI), organizacji non-profit, która istnieje aby promować standaryzację popularnych procesów biznesowych, jako środek wspierania rozwoju e-biznesu [6].

\section{Przegląd narzędzi analizy procesów biznesowych}

\subsection{Bizagi Modeler}

Bizagi BPMN Modeler to aplikacja umożliwiająca tworzenie graficznych diagramów, dokumentowanie, a także symulowanie procesów w notacji BPMN wytworzona przez firmę Bizagi w 2008 roku. $\mathrm{Z}$ wykorzystaniem modelera Bizagi, diagramy procesów mogą być publikowane między innymi w Wordzie, PDF, a także Sharepoint. Pozwala on na pracę w chmurze symultanicznie $\mathrm{z}$ innymi członkami organizacji [6].

\subsection{Lucidchart}

Lucidchart to aplikacja internetowa służąca do rysowania i udostępniania wykresów i diagramów wydana przez Lucid Software Inc. w 2008 roku [6]. Łączy w sobie elementy aplikacji Microsoft Excel, Adobe Photoshop oraz Aplikacji Google. Zbudowana została w oparciu o technologię HTML5 oraz JavaScript, co oznacza że aplikacja ta nie wymaga aktualizacji oprogramowania stron trzecich takiego jak Adobe Flash [7].

\subsection{Aris express}

ARIS Express to narzędzie przeznaczone do modelowania, analizy i zarządzania procesami biznesowymi stworzona przez Software AG w 2009 roku. Wydane jest na licencji freeware, co oznacza że można rozprowadzać ją za darmo, bez ujawnienia kodu źródłowego. Wspiera wiele notacji takich jak EPC, krajobrazy procesów, ERM i BPMN 2. Jedną z funkcjonalności wyróżniających ARIS Express na rynku narzędzi modelujących procesy biznesowe są fragmenty logiki, które można przechowywać i ponownie używać ich w innych modelach [8]

\subsection{Gliffy}

Gliffy to osadzona w chmurze aplikacja internetowa służąca do tworzenia diagramów wydana w 2007 roku przez dwóch programistów - Chrisa Kohlhardta i Clinta Dicksona [9]. Pozwala na tworzenie między innymi diagramów UML i Vienna, a także schematów pomieszczeń. Narzędzie to jest zintegrowane z serwisami JIRA i Confluence, co jest dużą zaletą tego rodzaju rozwiązań. Podobnie jak Lucidchart, Gliffy opiera się na technologii HTML5 [10].

\section{Metodyka badań porównawczych}

\subsection{Hipotezy i kryteria}

W niniejszym artykule zdecydowano przedstawić odpowiedzi na następujące pytania:

- Który program prezentuje najbardziej przejrzysty interfejs dla użytkownika?

- Który program zapewnia największą liczbę poradników?

- Który program zapewnia największą liczbę możliwości eksportu plików?

Starając się odnaleźć odpowiedzi na pytania badawcze zdefiniowano dwie hipotezy badawcze:

- H1. Program Lucidchart stanowi najbardziej kompleksowe rozwiązanie dla zespołu projektu.

- H2. Program Aris Express zapewnia największą liczbę możliwości importu oraz eksportu plików.

Przy ocenie użyteczności badanych programów, zastosowano następujące kryteria:

- $\quad$ przejrzystość interfejsu - intuicyjność i prostota modelowania procesów biznesowych wartościowana w punktach;

- wygląd aplikacji - prezentacja pola roboczego, zakładek z narzędziami oraz prezentacja ogólna aplikacji wartościowana w punktach;

- $\quad$ łatwość rejestracji - proces rejestracji nowego użytkownika wartościowany w punktach;

- jakość poradników w postaci dokumentacji ocena wartościowości oraz przydatności poradników w postaci dokumentacji wartościowana w punktach;

- jakość poradników w postaci filmów online ocena wartościowości oraz przydatności poradników w postaci filmów online wartościowana w punktach; 
- $\quad$ liczba poradników w postaci dokumentacji - ocena ilości dostępnych poradników w postaci dokumentacji wartościowana w punktach;

- liczba poradników w postaci filmów online ocena ilości dostępnych poradników w postaci filmów online wartościowana w punktach;

- dostępne funkcjonalności - ocena zero jedynkowa, czy aplikacja posiada konkretną funkcjonalność.

Podczas przeprowadzania scenariuszy w programach, przyznawano 1 punkt za każdą dostępną (posiadaną) funkcjonalność, natomiast 0 punktów za jej brak.

W celu uzyskania większej ilości informacji, podkategorie: import oraz eksport plików, zostały zawarte $\mathrm{W}$ odrębnym zestawieniu niż dostępne funkcjonalności, natomiast kryterium również przewiduje 1 punkt za posiadaną funkcjonalność oraz 0 punktów za jej brak.

Kolejne kryteria również zostały objęte skalą punktową, programom można było przyznać od 0 do 5 punktów za przejrzystość interfejsu, wygląd aplikacji, łatwość rejestracji, jakość poradników w postaci dokumentacji, jakość poradników w postaci filmów online, ilość poradników w postaci dokumentacji oraz ilość poradników w postaci filmów online.

Ocena każdego z kryteriów była wyższa proporcjonalnie do liczby zdobytych punktów.

\subsection{Scenariusze badawcze}

W celu zbadania wymienionych kryteriów, w każdym z programów zostały wykonane analizy następujących procesów:

- wybór samochodu do zakupu dla rodziny 6 osobowej;

- $\quad$ obsługa zamówienia w sklepie internetowym;

- $\quad$ produkcja ołówków w zakładzie przemysłowym;

- kontrola stanu samochodu przed użytkowaniem.

\section{Rezultaty badań $i$ ich analiza}

Niniejszy rozdział ma na celu prezentację uzyskanych rezultatów, które są wynikiem przeprowadzonej analizy porównawczej badanych programów na podstawie eksperymentów modelowania scenariuszy badawczych. Rezultaty w postaci zbiorczej zostały zaprezentowane na Tabeli 1.

Program Lucidchart posiada najwyższą liczbę dostępnych funkcjonalności wytypowanych do przeprowadzenia badań (ex aequo z Bizagi Modeler). Kolejne w kolejności programy Aris Express i Gliffy mają wyraźnie mniejszą liczbę punktów w tym kryterium co przedstawiono $\mathrm{w}$ formie wizualnej na Rysunku 1.

Kolejnym kryterium branym pod uwagę podczas badań był import i eksport plików za pośrednictwem programów. W tym kryterium również najwyższą liczbę punktów zdobyły programy Lucidchart oraz Bizagi Modeler, gdzie ten drugi miał większą liczbę punktów w kategorii eksportu plików. Omawiane kryterium jest istotne jeżeli zespół pracowników pracuje na nie ujednoliconym środowisku i konieczne jest przesyłanie plików z modelami w celu dalszej pracy. Programy Aris Express oraz Gliffy ponownie wyraźnie odstają od pierwszych dwóch programów. Program Gliffy nie zdobył żadnego punktu zarówno przy imporcie jak i eksporcie plików, co bardzo zmniejsza jego atrakcyjność. Wyniki omawianego kryterium zostały przedstawione w formie graficznej na Rysunku 2.

Tabela 1: Zbiorcze zestawienie punktów przyznanych programom

\begin{tabular}{|c|c|c|c|c|}
\hline Kryterium Program & $\begin{array}{l}\text { Bizagi } \\
\text { Modeler }\end{array}$ & $\begin{array}{l}\text { Lucid- } \\
\text { chart }\end{array}$ & $\begin{array}{c}\text { Aris } \\
\text { Express }\end{array}$ & Gliffy \\
\hline $\begin{array}{c}\text { Dostępne } \\
\text { funkcjonalności }\end{array}$ & 8 & 8 & 4 & 2 \\
\hline Import plików & 3 & 3 & 1 & 0 \\
\hline Eksport plików & 5 & 4 & 1 & 0 \\
\hline $\begin{array}{l}\text { Wygląd } \\
\text { aplikacji }\end{array}$ & 3 & 4 & 2 & 2 \\
\hline $\begin{array}{l}\text { Przejrzystość } \\
\text { interfejsu }\end{array}$ & 3 & 4 & 2 & 2 \\
\hline $\begin{array}{l}\text { Łatwość } \\
\text { rejestracji }\end{array}$ & 4 & 5 & 4 & 5 \\
\hline $\begin{array}{c}\text { Jakość } \\
\text { poradników w } \\
\text { postaci } \\
\text { dokumentacji }\end{array}$ & 4 & 5 & 3 & 4 \\
\hline $\begin{array}{c}\text { Jakość } \\
\text { poradników w } \\
\text { postaci filmów } \\
\text { online }\end{array}$ & 4 & 4 & 3 & 4 \\
\hline $\begin{array}{c}\text { Ilość } \\
\text { poradników w } \\
\text { postaci } \\
\text { dokumentacji }\end{array}$ & 4 & 5 & 3 & 5 \\
\hline $\begin{array}{c}\text { Ilość } \\
\text { poradników w } \\
\text { postaci filmów } \\
\text { online }\end{array}$ & 4 & 5 & 3 & 4 \\
\hline Suma & $42 / 59$ & $47 / 59$ & $27 / 59$ & $30 / 59$ \\
\hline
\end{tabular}

Ze względu na prostotę oraz otwartość na niewielką możliwość konfiguracji przestrzeni roboczej Lucidchart zdobył najwyższą liczbę punktów w kategorii wyglądu aplikacji oraz kategorii przejrzystości interfejsu, gdzie taką samą liczbę punktów (4 punkty) zdobył program Gliffy.

Rejestracja we wszystkich programach przebiegła w dość podobny sposób, nie powodując nieoczekiwanych problemów, dlatego programy uzyskały niemalże identyczna liczbę punktów w kategorii prostoty rejestracji. Programy Bizagi 
Modeler i Aris Express zostały pozbawione punktu za konieczność nieco dłuższego przeszukania strony producenta w celu znalezienia formularza rejestracyjnego. W formie graficznej przedstawione zostały omówione trzy kryteria jako cechy niemierzalne na Rysunku 3.

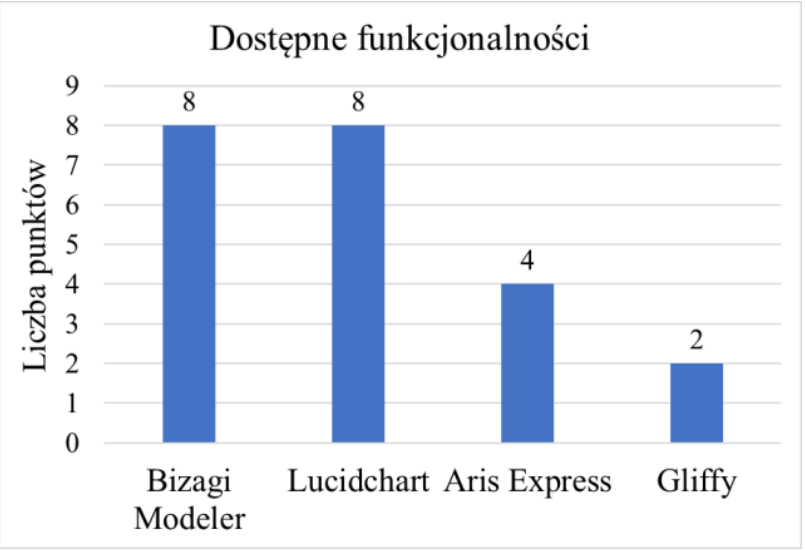

Rysunek 1: Wykres przedstawiający liczbę punktów zdobytych przez programy w zakresie dostępnych funkcjonalności.

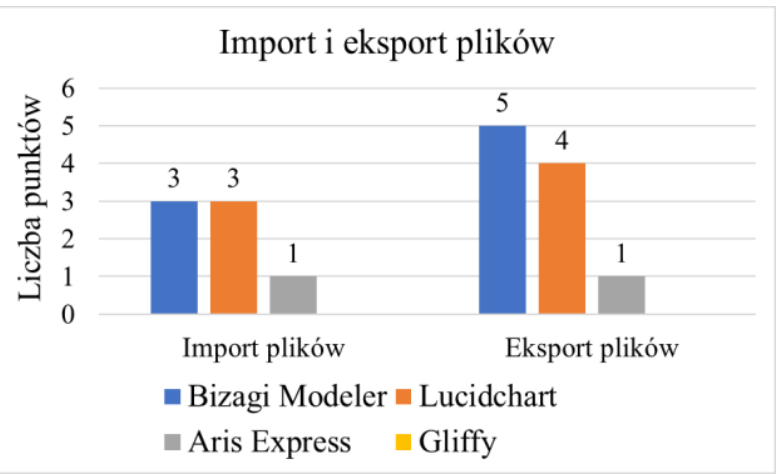

Rysunek 2: Wykres przedstawiający liczbę punktów zdobytych przez programy w zakresie importu i eksportu plików.

Zaskakująco każdy z badanych programów posiada nie małą ilość poradników w postaci dokumentacji oraz w postaci filmów online zarówno na stronach producentów programów jak i forach oraz darmowych stronach do zamieszczania filmów online. W kategoriach ilości poradników w postaci dokumentacji oraz filmów online największą ilość punktów zdobył program Lucidchart, przy czym dwa razy otrzymał maksymalną liczbę punktów, 5. Zaraz po nim uplasował się niewiele gorszy Gliffy, Bizagi Modeler oraz na ostatnim miejscu Aris Express.

W przypadku badanych programów ilość poradników została oceniona niemalże identycznie jak ich jakość, która w naszej ocenie jest ważniejsza od ilości. W przypadku kryterium jakości poradników w postaci dokumentacji i filmów online ponownie największą ilość punktów zdobył Lucidchart, na drugim miejscu ex aequo Bizagi Modeler oraz Gliffy, a na ostatnim miejscu Aris Express z trzema punktami w każdym z kryteriów. Wyniki w formie graficznej zbioru kryteriów dotyczących jakości oraz ilości poradników w postaci dokumentacji oraz filmów online przedstawiono na Rysunku 4.

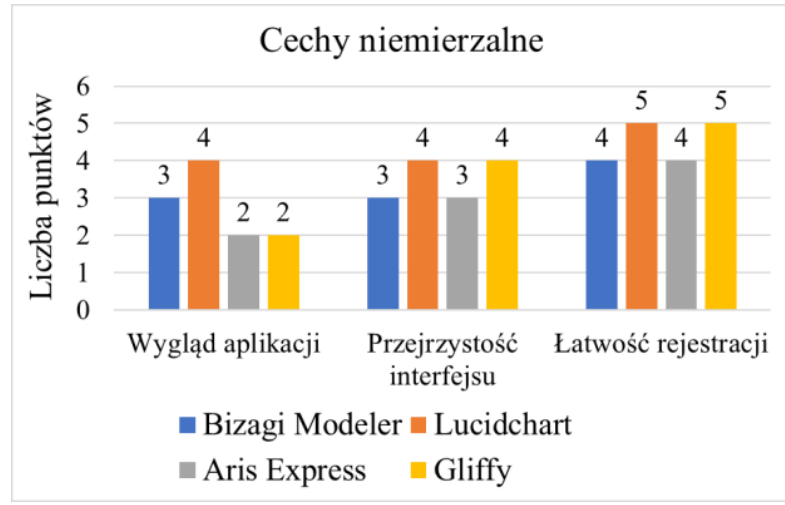

Rysunek 3: Wykres przedstawiający liczbę punktów zdobytych przez programy w zakresie cech niemierzalnych.

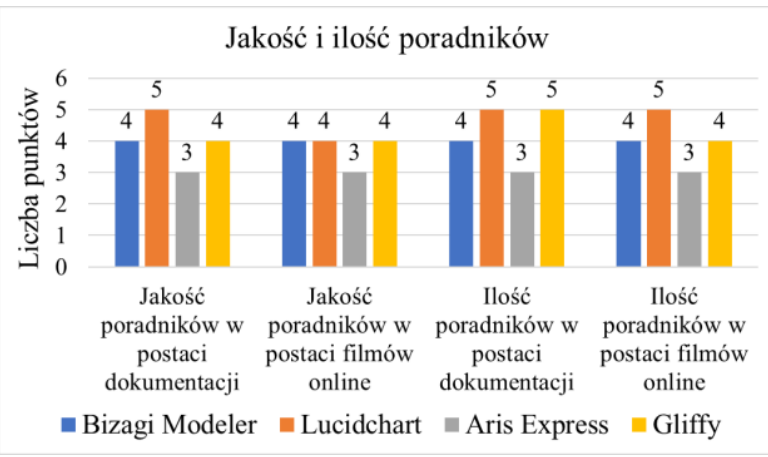

Rysunek 4: Wykres przedstawiający liczbę punktów zdobytych przez programy w zakresie jakości i ilości poradników.

\section{Wnioski}

Celem niniejszego artykułu było przedstawienie wybranych narzędzi do modelowania diagramów BPPMN, razem $\mathrm{z}$ oceną ich funkcjonalności. Zadanie to zostało zrealizowane poprzez zastosowanie scenariuszy testowych badających konkretne możliwości każdego $\mathrm{z}$ badanych narzędzi. Ostateczny rezultat każdego $\mathrm{z}$ programów składa się $\mathrm{z}$ dwóch części składowych oceny właściwości mierzalnych i niemierzalnych.

$\mathrm{Z}$ pośród badanych programów - Bizagi Modeler, Lucidchart, Aris Express i Gliffy - narzędziem które zdobyło najwięcej punktów jest Lucidchart, z przewagą 5 punktów nad następnym programem, czyli Bizagi Modeler. Warto zaznaczyć, że w części mierzalnej oba te narzędzia zdobyły dokładnie taką samą liczbę punktów, jednak łatwość w obsłudze i przyjemny interfejs sprawiły że Lucidchart jest wyżej klasyfikowanym oprogramowaniem. $\mathrm{Na}$ trzecim miejscu plasuje się Gliffy, jednak jego przewaga nad narzędziem z najniższą ilością punktów, Aris Express, wynosi jedynie 3 punkty.

Warto zauważyć że „zwycięski” program Lucidchart - zdobył niespełna $80 \%$ wszystkich możliwych punktów, co oznacza że niestety nie jest to 
narzędzie idealne, niemniej jednak będzie dobrze sprawdzać się jako modeler dla diagramów BPMN.

W ramach badań przedstawiono pierwszą hipotezę, że program Lucidchart stanowi najbardziej kompleksowe rozwiązanie dla zespołu projektu. Program ten zdobył największą liczbę punków w sumie biorąc pod uwagę każde kryterium, dlatego należy przyjąć pierwszą hipotezę.

Druga hipoteza zdefiniowana, program Aris Express zapewnia największą liczbę możliwości importu oraz eksportu plików. Zwycięski sumarycznie program Lucidchart oraz drugi $\mathrm{w}$ zestawieniu program Bizagi Modeler zapewniają większą liczbę możliwości importu oraz eksportu plików. W efekcie tego należy odrzucić drugą hipotezę, ponieważ istnieją programy zapewniające większa liczbę możliwość importu oraz eksportu plików.

Podsumowując zaprezentowane wyniki badań powinno się stwierdzić, że pierwsza postawiona hipoteza jest prawdziwa, natomiast druga postawiona hipoteza okazałą się nieprawdziwa.

\section{Literatura}

[1] S. Bechhofer, M. Hauswirth, J. Hoffmann, M. Koubarakis: The Semantic Web: Research and Applications. Springer, 2008.

[2] Podstawy procesu biznesowego, https://www.mfiles.pl/pl/index.php/Proces_biznesowy [06.05.2021].

[3] M. Dumas, M. La Rosa, J. Mendling, H. A. Reijers: Fundamentals of Business Process Management. Springer, 2013.

[4] Informacje o Aris Community, https://www.ariscommunity.com/, [06.05.2021].

[5] Przewagi programu Gliffy, https://www.cnet.com/news/gliffy-the-online-visiokiller/, [06.05.2021].

[6] Eksport oraz publikowanie w Bizagi Modeler, https://help.bizagi.com/bpmsuite/en/index.html?where_to_share.htm, [06.05.2021].

[7] Przegląd usług dla program Gliffy, https://www.gliffy.com/pricing, [06.05.2021].

[8] Podstawy analizy procesów, https://www.mfiles.pl/pl/index.php/Analiza_proces\%C 3\%B3w, [06.05.2021].

[9] Przegląd usług dla program Lucidchart, https://lucid.app/pricing/lucidchart\#/pricing, [06.05.2021].

[10] Podstawy o Business Process Management Initiative, https://searchcio.techtarget.com/definition/BusinessProcess-Management-Initiative-BPMI, [06.05.2021] 